Claremont Colleges

Scholarship@ Claremont

Pitzer Faculty Publications and Research

Pitzer Faculty Scholarship

$12-1-2008$

\title{
Individuals and Populations: How Biology's Theory and Data have Interfered with the Integration of Development and Evolution
}

David S. Moore

Pitzer College

\section{Recommended Citation}

Moore, David. "Individuals and Populations: How Biology's Theory and Data have Interfered with the Integration of Development and Evolution." Integrating Development and Evolution in Psychology. Spec. issue of New Ideas in Psychology 26.3 (2008): $370-386$.

This Article - postprint is brought to you for free and open access by the Pitzer Faculty Scholarship at Scholarship @ Claremont. It has been accepted for inclusion in Pitzer Faculty Publications and Research by an authorized administrator of Scholarship @ Claremont. For more information, please contact scholarship@cuc.claremont.edu. 
Running head: Individuals and Populations

The content of this open-access post-print article is the same as that contained in the published article with the following reference:

Moore, D. S. (2008). Individuals and populations: How biology's theory and data have interfered with the integration of development and evolution. New Ideas in Psychology, 26, 370 - 386.

Individuals and populations: How biology's theory and data have interfered with the integration of development and evolution

David S. Moore

Pitzer College \& Claremont Graduate University

July 19,2007 
Individuals and Populations 1

Running head: Individuals and Populations

Individuals and populations: How biology's theory and data have interfered with the integration of development and evolution

July 19, 2007 


\begin{abstract}
Research programs in quantitative behavior genetics and evolutionary psychology have contributed to the widespread belief that some psychological characteristics can be “inherited" via genetic mechanisms. In fact, molecular and developmental biologists have concluded that while genetic factors contribute to the development of all of our traits, non-genetic factors always do too, and in ways that make them no less important than genetic factors. This insight demands a reworking of the Modern Evolutionary Synthesis, a theory that defined evolution as a process involving changes in the frequencies of genes in populations, and that envisioned no role for experiential factors now known to play essential roles in adaptive trait development. Furthermore, since evolution has been taken to be strictly a population-level phenomenon while development affects individuals, the two have been understood to require different levels of analysis; this understanding has given rise to incompatible research programs. This state of affairs is untenable because development and evolution mutually influence one another in fundamental ways, several of which are detailed in this article. The balance of this paper considers the conceptual problem that has arisen because understandings generated by developmental scientists cannot be enhanced by studies designed merely to account for variation across populations. Because the theoretical conceptions and methodological tools used to study development and evolution have produced non-corresponding sets of information about these closely related and mutually influential biological processes, these conceptions and tools are interfering with the establishment of a unified theory of biology that encompasses both phenomena.
\end{abstract}


Individuals and populations: How biology's theory and data have interfered with the integration of development and evolution

The phrase "new ideas in psychology" can refer either to influential ideas that have emerged in the writings of psychologists or to ideas that have emerged in allied fields and that are now influencing thinking among psychologists. Such bidirectional influence has been easy to observe recently at the interface of evolutionary biology and psychology. ${ }^{1}$ Among the ideas currently sweeping through psychology is the idea that many human psychological characteristics can be understood when subjected to evolutionary analysis. The collection of scientists who call themselves "evolutionary psychologists"-including such theorists as Leda Cosmides, John Tooby, Steven Pinker, David Buss, Martin Daly, Margo Wilson, and Donald Symons—-have attempted to explain cognitive phenomena by first inferring what sorts of problems our huntergatherer ancestors in the Pleistocene epoch might have needed to solve in order to survive and reproduce, and then determining how natural selection operating on such a population might have led to the mental structures that characterize modern people. As a result of this work, the psychological literature has grown full of references to putative evolved psychological characteristics such as an innate "mental organ" that creates grammatical sentences (Chomsky, 1975), a domain-specific cognitive module dedicated to detecting individuals who are cheating in social exchanges (Cosmides, 1989), and a modular "theory-of-mind mechanism" that uses a social partner's behaviors to infer her mental states (Baron-Cohen, 1995).

Meanwhile, molecular biologists, developmental biologists, and neuroscientists have discovered that biological characteristics always develop as a result of complex 
interactions between genetic and non-genetic factors. Given that our psychological characteristics reflect the structure and function of the biological organ in our heads, psychological characteristics, too, always reflect the interaction of genetic and environmental factors. Although the new ideas emerging in these diverse camps have made this a very exciting time to be a psychological scientist, aspects of these ideas have illuminated existing problems in our long-established theory of evolution that have yet to be solved. To understand the source of these problems, some knowledge about the historical origins of our current theory of evolution — and the role of development in that theory—will be helpful.

A brief history of ideas about the relationship between development and evolution

The idea that evolution and development are integrally related is very old (see Gould (1977) for a thorough discussion of this idea in antiquity), but for the present purposes, it is enough to note the presence of this idea in 1859 , at the inception of modern evolutionary theory, when Darwin published The Origin of Species. Darwin—building on the speculations in 1794 of his grandfather, Erasmus Darwin—devoted sections of both The Origin of Species and The Descent of Man to embryological considerations, noting in the latter that his case for common descent of all mammals was strengthened significantly by the observation that "the embryo of man closely resembles that of other mammals" ( $p$. 182). Just 7 years later, Ernst Haeckel concluded that "ontogeny [i.e., the development of an organism over its lifetime] is the short and rapid recapitulation of phylogeny [i.e., the evolution of a species across generations]. ...During its own rapid development...an individual repeats the most important changes in form evolved by its ancestors during their 
long and slow paleontological development" (1866 vol.2, p. 300, cited in Gould, 1977, p. 76-77).

Although it turned out that Haeckel's conclusion was wrong, many biologists have continued to believe that our understandings of development and evolution can and should inform one another. For example, Walter Garstang wrote in 1922 that "through the whole course of Evolution, every adult...has been the climax of a...life-cycle, which has always intervened between adult and adult...[Evolution] has never been a direct succession of adult forms, but a succession of ontogenies" (p. 82). Exploring the relationship between development and evolution from this perspective led Garstang to suggest that evolutionarily adaptive traits first arise when developmental events lead descendant generations to have altered versions of characteristics that were present in their ancestors. He concluded "Ontogeny does not recapitulate Phylogeny: it creates it" (p. 98).

In the third edition of his 1930 book Embryos and evolution (renamed Embryos and ancestors in 1958), Gavin de Beer elaborated on this idea by co-opting one of Haeckel's terms - heterochrony - to explain how alterations across generations in the timing of the development of particular characteristics could be an important evolutionary force. Noting that changes in the timing of developmental events could lead to novel characteristics, de Beer pointed out that via such a mechanism, developmental events could potentially drive evolution. For example, if characteristics that are present in ancestors only when they are juveniles begin to be retained into adulthood in descendant generations - perhaps through a slowing down of the development of those characteristics, a process known as neoteny_natural selection would be able to 
'evaluate' the adaptive quality of those characteristics in the adults, and potentially permit them to appear in subsequent generations of adult descendants.

In fact, such a phenomenon appears to have been important in the evolution of human beings; Gottlieb (1992) discussed one example of a neotenous characteristic that was present in our ancestors when they were juveniles, but that now characterizes adult humans:

"An example of neoteny in our own species...is our retention into adulthood of the cranial flexure of the fetal period (eyes and nose facing at right angle to spine). This embryonic condition is exhibited by all other mammals, which then deviate [during development] such that the eyes and nose form a more or less continuous line with the angle of the spinal cord in the adult form. The retention of this embryonic feature in [adult] humans is accompanied by others, such as the retention of the fetal skull shape and nonopposable big toe, all of which are necessary to, or are correlated with, upright walking posture" (p. 100).

The arguments that de Beer advanced about the importance of developmental events to evolutionary processes continue to enjoy support among contemporary biologists (Buckley, Alcobendas, García-París, \& Wake, 2007; Gould, 2002; McNamara \& McKinney, 2005).

In the late 1930's, a group of biologists, including such luminaries as Ernst Mayr, Julian Huxley, and Theodosius Dobzhansky, began trying to synthesize Darwin's theory of evolution-by-natural-selection with the theory of the gene that had emerged from the work of Gregor Mendel, August Weismann, Wilhelm Johannsen, and Thomas Hunt 
Morgan. Their achievement, known today as "The Modern Synthesis," continues to be accepted by virtually all contemporary biologists as the theory of evolution. However, in spite of how astonishingly successful the Modern Synthesis has been in its ability to make sense of the disparate data emerging from the fields of molecular biology, genetics, biochemistry, and cell biology, one major omission in the theory continues to be problematic: the theory gives virtually no role to development, in spite of how important developmental processes obviously are to all biological phenomena. As Moore noted in 2001, "the exclusion of developmental data from the modern synthesis continues to interfere with efforts to forge a comprehensive theory of evolution" (p. 167).

Some of the architects of the modern synthesis-including Dobzhansky, Huxley and Sewall Wright, for example-were aware of the importance of development, but they also knew that a working understanding of many developmental problems (e.g., cell differentiation, among others) was still well beyond the grasp of biology. Nevertheless, the biologists who contributed to the modern synthesis - if they were concerned about the problem of development at all—recognized that by temporarily ignoring developmental issues, they would be able to produce an almost-comprehensive theory of biology that would have extraordinary explanatory power. Consequently, they made the decision to define evolution as a process involving changes in the frequencies of genes in populations, a move that allowed them to disregard the developmental processes that operate on individuals, while still producing a theory on the genetics of evolution.

Biologists have operated successfully under this theory for over 6 decades, but recent insights from molecular biology, developmental biology, and the neurosciences are forcing reconsideration of several fundamental issues, including how development should 
be integrated into the modern theory of evolution (Gottlieb, 1992; Lickliter \& Honeycutt, 2003); whether or not biologists' traditional conceptualization of heredity is up to the tasks currently assigned to it (Griffiths \& Gray, 2001); and what data from studies of population genetics can tell us about the appearance of characteristics in individual development. The current paper will focus on this final issue. Psychological phenomena, in particular, can illuminate some of the problems that must be solved before a comprehensive theory of evolution can be articulated.

How recent discoveries in molecular and developmental biology laboratories have highlighted problems in The Modern Synthesis The past 10 years have seen an explosion of new information about the workings of the human genome (Guttmacher \& Collins, 2005). Even as approximately 3 billion dollars were spent in the Human Genome Project's effort to map our DNA, the frontiers of research expanded to include work on proteomics — research on the full complement of proteins present in given cells, tissues, or organisms - and epigenomics - research on how "non-genetic" features of DNA and its immediate environment (e.g., methylation patterns and histone modifications) determine how genes actually function in normally developing organisms (Brena, Huang, \& Plass, 2006). Among the conclusions that can be drawn from this work is that it is a misleading simplification to maintain that genetic factors can cause developmental outcomes independently of the contexts in which the genes of interest are operating $^{2}$ (Eisenberg, 2004; Meaney, 2007; Robert, 2006). In fact, DNA is unable to make any contributions to development without the help of non-genetic factors present in its local environment (Dennett, 1995; Keller, 2000; Oyama, 1992), so development is best thought of as resulting from a collaboration between all of these 
factors (Griffiths \& Gray, 1994). Such an understanding emphasizes the fact that development is an epigenetic process. Among the best examples of DNA's dependence on its context is the phenomenon of alternative splicing, wherein a single genetic sequence can serve different functions depending on the particular cell in which it is being 'decoded;' although such alternative splicing was once thought to be a relatively rare phenomenon, it is now believed to characterize more than 30 percent of the genedecoding operations that occur during normal development (Neumann-Held, 1998).

If only the non-genetic factors that contribute to development were all themselves constructed through the actions of genes, one might still hope to retain the notion that 'gene complexes' are able to function autonomously, but recent research on gene expression indicates that the environment outside of our bodies—what psychologists typically think of as 'nurture'-plays essential roles in this process (Gottlieb, 2004; Harper, 2005; Meaney \& Szyf, 2005; Weaver et al., 2007). For instance, it has been known for at least two decades that specific experiences can alter the release of hormones into our bloodstreams, and that some of these hormones-including, but not limited to, cortisone, the estrogens, and testosterone — can then diffuse into cell nuclei and bind with hormone receptors to form a steroid/receptor complex which itself can bind with DNA, and thereby regulate the rate at which genes produce their protein products (Yamamoto, 1985). With the discovery of a number of such mechanisms of gene regulation, several theorists have begun to think of the genome as fundamentally reactive (Gilbert, 2003), in recognition of the fact that it is highly responsive to features of the environment.

Paradoxically, then, one of the most important insights to emerge from focused study of how genetic factors contribute to development is the realization that non-genetic 
factors are just as important as genes in producing developmental outcomes, no matter what outcome is being considered. The dissemination of this conclusion has been hindered by widely reported findings from studies by quantitative behavior geneticists (e.g., Deater-Deckard, Petrill, Thompson, \& DeThorne, 2006; Wainwright, Wright, Geffen, Luciano, \& Martin, 2005) and from studies by evolutionary psychologists (e.g., Bernard, Mills, Swenson, \& Walsh, 2005; De Cruz, 2006; Hampson, van Anders, \& Mullin, 2006), all of which have supported the (largely foregone) conclusion that our characteristics are influenced by genetic factors. Nonetheless, while it is not always made clear in their writings (e.g., Deater-Deckard et al., 2006; Yamagata et al., 2006), leading quantitative behavior geneticists have acknowledged that their research does not assess the relative importance of genetic and non-genetic contributions to individual development (Plomin, 1994), and leading evolutionary psychologists have acknowledged that no "sane biologist would ever dream of proposing" that human behavior is genetically determined (Pinker, 2002, p. 112). Thus, although genetic factors obviously contribute to the development of all human characteristics, it is now widely understood among biologists that the presence of particular genes in a body is not enough to singlehandedly cause the development of either psychological or biological traits (biologists' vernacular use of the linguistic shorthand, "the gene for ____, notwithstanding).

One of the consequences of this emerging understanding of gene function is that our received theory of evolution-The Modern Synthesis — cannot be understood to be a comprehensive theory of evolution. According to the Modern Synthesis, evolution occurs when random genetic mutations generate novel characteristics - phenotypes - that can be selected by nature if they are adaptive, and thereby become more prevalent in descendent 
populations than they were in ancestral populations. This conceptualization works well as long as the only source of novel phenotypes is genetic, a belief that received important support from the strong arguments of biologist August Weismann at the end of the $19^{\text {th }}$ century (Barker, 1993), and that was effectively enshrined by Francis Crick six decades later as biology's “Central Dogma” $(1958,1970)$. However, because we now know that novel phenotypes are constructed via the co-action of both genetic and non-genetic factors - an arrangement that precludes the possibility that either type of factor might be more important to the process than the other (Robert, 2006) — the Modern Synthesis will have to be reworked.

\section{Modifying the Modern Synthesis to reflect the importance of behavior}

The discovery that all phenotypes are built during development in an epigenetic process involving the co-action of genetic and non-genetic factors (Gottlieb, 1992) means that animals' behaviors can have potentially important roles in evolutionary processes, a possibility not acknowledged in the canonical account of evolution. For example, if the behaviors of a population of animals lead them into novel environments, novel processes could influence the development of their offspring, potentially producing adaptive characteristics, either directly or indirectly. Because subsequent generations produced by the offspring of these pioneering animals would be raised in the same environments as their parents were, and would therefore experience substantially the same developmental processes, these descendants would likewise develop the adaptive characteristics that contributed to their ancestors' survival.

The potential importance of such a sequence of events, which Gilbert Gottlieb (1987; Johnston \& Gottlieb, 1990) first identified and then named behavioral 
neophenogenesis, can be illustrated by considering the recent discovery that genes associated with the ability to digest milk in adulthood seem to have evolved independently in European and African populations. This finding appears to reflect convergent evolution attributable "to a strong selective force, adult milk consumption" (Tishkoff et al., 2007, p. $37-38$ ). Following the discovery 4 decades ago that adult human populations vary significantly in their ability to digest milk (Cuatrecasas, Lockwood, \& Caldwell, 1965), scores of studies examined the geographical distributions of these populations; taken together, the studies revealed that the ability to digest dairy products - i.e., to absorb lactose, the sugar present in mammalian milks — is most common "in northern European populations ( $>90 \%$ in Swedes and Danes), decreases in frequency across southern Europe and the Middle East ( 50\% in Spanish, French, and pastoralist [i.e., herding] Arab populations) and is low in non-pastoralist Asian and African populations ( $\sim 1 \%$ in Chinese [populations])" (Tishkoff et al., p. 31). Importantly, the ancestors of the lactose-absorbing northern Europeans were dairying peoples, whereas the ancestors of the lactose-malabsorbing East Asians, for instance, were not. After testing several hypotheses that could account for the observed pattern of data, Durham (1991) concluded that "the genes responsible for adult lactose absorption have evolved to high frequencies in populations that (1) have a long-standing tradition of dairying and fresh milk consumption, and (2) live in environments of low ultraviolet radiation where vitamin D and metabolic calcium are chronically deficient" (p. 279). Because both of these conditions characterize populations able to digest milk, Durham concluded that the data point to "the role of culture in the evolution of adult lactose 
absorption" (p. 280) and that "dairying and the genes of adult lactose absorption coevolved" (p. 282). Similarly, Tishkoff et al. (2007) wrote:

Considering the symptoms of lactose intolerance, which includes water loss from diarrhea, individuals who ... could tolerate milk could have had a very strong selective advantage. Because the selective force, adult milk consumption, is associated with the cultural development of cattle domestication, the recent and rapid spread of [genes associated with the ability to digest milk in adulthood], together with the practice of pastoralism [in those East African populations recently found able to absorb lactose], is an excellent example of ongoing adaptation in humans and coevolution of genes and culture" (p. 36)

Although some theorists have recognized for decades that a population's behavior (i.e., culture) can potentially have direct influences on biological evolution (see, for example, several contributed papers in Montagu, 1962), empirical evidence of such phenomena has now begun to appear (McComb \& Semple, 2005; Tishkoff et al., 2007). In addition, a substantial literature now exists that describes computational models that support the likelihood that cultural processes such as female infanticide and sex-biased abortions have evolutionary consequences (Laland, Kumm, \& Feldman, 1995) and that human handedness reflects gene-culture coevolution (Laland, Kumm, Van Horn, \& Feldman, 1995). These results underscore the need to further integrate development into our theory of evolution, a theory that has focused for 7 decades on the role of genetic factors alone, while excluding roles for the experiences that normally influence individual development.

\section{Populations vs. individuals: Historical approaches to evolution and development}

These signs that development is beginning to be reintegrated into evolutionary theory represent a welcome step forward, but such reintegration will ultimately reveal an intractable problem that reflects the history of our current ideas about the two 
phenomena. Although development and evolution share an important relationship, they have historically been understood to require different levels of analysis; the history of thought about these phenomena has left us with a large conceptual stumbling block that to date has prevented us from achieving a comprehensive understanding of their relationship.

At least since 1894—when Wilhelm Roux founded a journal specifically to publish the work of experimental embryologists - the study of development has focused on the mechanical causes of ontogeny in individual organisms. In contrast, scholars of evolution have always explained phylogeny by studying variability in populations; this approach can be traced initially to Charles Darwin, who strongly emphasized the importance of variability in the Origin of Species.

Although Darwin is often erroneously remembered by non-biologists as the man who introduced the idea of evolution to the world, his major contribution according to most evolutionary biology textbooks is "population thinking" (Ariew, in press). Prior to Darwin, most naturalists considered the variations detectable among a group of individuals to be "errors," that is, departures from an essential Aristotelian type (eidos) that were caused by diverse forces keeping the varying individuals from their "natural" state (Sober, 1994). In contrast, Darwin understood that the variation seen among individual members of a species played an important role in the natural process that gives rise to species. Consequently, evolutionary biology has been characterized by "population thinking" ever since. Mayr, in particular, extolled the virtues of this point of view in his 1959 essay “Typological versus Population Thinking.” Building on this perspective—-and on the work of very early geneticists such as Gregor Mendel and T.H. Morgan - a group 
of biologists including R.A. Fisher and J. B. S. Haldane established the field of population genetics, a discipline founded as the study of the causes of individual differences, not the causes of individual organisms' characteristics.

Quantitative behavior genetics - the branch of population genetics devoted to exploring genetic contributions to behaviors - attempts to account for phenotypic variation in a population by finding correlations between the presence of particular genetic differences and the presence of particular phenotypic differences. Said another way, the goal of quantitative behavior geneticists is to identify genetic factors that can account for the individual differences observed in members of a population. One method such behavior geneticists use to accomplish this is the twin study, the strongest form of which involves studying monozygotic (MZ, or "identical") twins who were "separated at birth," and comparing their concordance on a given trait with the concordance on the same trait of separated-at-birth dizygotic (DZ, or "fraternal") twins. Because MZ twins share a full complement of identical genes whereas DZ twins share, on average, only half of their genes, greater concordance among the MZ than the $\mathrm{DZ}$ twins in such studies is taken as evidence for genetic contributions to the trait in question. In the language of quantitative behavior genetics, variation in genetic factors account for measured variation in the trait being studied.

Although the goal of this endeavor is to explain individual differences, behavior geneticists who rely on twin studies never actually study the factors that cause the development of traits in individuals. Instead, they calculate correlations that reflect the strength of the relationship between genetic variation in a population, and variation across that population in a particular phenotype-a developmental outcome. 
Consequently, the results of such studies do not reveal anything about what causes the traits in question in individuals; this is the interpretation-of-correlations problem that all undergraduate psychology students learn about in their first statistics classes. Obviously, it is possible to study the mechanical causes of the development of a trait in a variety of individuals and thereby learn what exactly causes these individuals to vary from one another on that characteristic, but in practice, the study of individual psychological or behavioral differences in human beings has virtually never proceeded in this way. ${ }^{3}$

Why the differences between population approaches and developmental approaches are a problem: An overview

While quantitative behavior geneticists have been studying the phenomena of interest to them, developmentally oriented biologists, psychologists, and psychobiologists have pursued a program of research designed to reveal the antecedent, mechanical causes of development in individual organisms, by conducted experiments that entail intervening in normal development. Thus, the efforts of developmentalists on one hand and quantitative behavior geneticists on the other have given rise to parallel sets of information, one about developmental influences on individual organisms and one about how genetic variation is correlated with phenotypic variation across populations. Both endeavors have generated large quantities of data, but they represent fundamentally different approaches to their objects of study, and the gulf in comprehension that has emerged because understandings in one domain cannot be used to enhance understandings in the other domain represents a serious conceptual problem.

This problem arises because development and evolution influence one another in fundamental ways; they are interconnected in ways that are apparent even before one 
considers the nature of their interactions in detail. Developmental processes produce all of the characteristics that natural selection — an evolutionary process—operates on; the characteristics that are "visible" to natural selection are phenotypic characteristics that are always realized in development. ${ }^{4}$ Likewise, by selecting adaptive characteristics in one generation, nature - that is, the evolutionary process of natural selection —indirectly influences how those characteristics develop in later generations. Thus, development and evolution could hardly share a closer relationship.

If the processes of development and evolution were not so intertwined, perhaps it would not be a problem that developmentalists and population/behavior geneticists have historically studied different phenomena. After all, there are many other scientific domains in which disparate sets of information have sometimes arisen from different levels of analysis, and in which such outcomes have not necessarily been bothersome; an understanding of the fluid dynamics that characterize a stream of water, for instance, can generally be achieved without considering the motion that characterizes the behavior of individual water molecules in the stream (i.e., the activity that gives rise to Brownian motion). The existence of such scientific domains has emboldened quantitative behavior geneticists to claim that it is reasonable for them to study variation across populations at one level of analysis while developmentalists study the emergence of phenotypic characteristics at a different level of analysis (Bouchard \& Segal, 1985); Mitchell (2003, p. 186) and Tabery (2007) have called this a form of "isolationist pluralism" wherein the two types of researchers simply accept as unproblematic the fact that they are studying phenomena at different levels of analysis. However, the repercussions of the wildly different approaches to explanation taken by those interested in the causes of individual 
development and those interested in accounting for variation across populations are problematic because of the profound influences that evolutionary and developmental processes have on one another; the fact that we are now in possession of two noncorresponding sets of information about closely related biological processes is worrisome indeed. To put the problem starkly, a species is a population that is subject to evolutionary forces, but it is composed of individuals that are subject to developmental forces; although development and evolution influence one another, the theoretical conceptions and methodological tools we have used to study them continue to interfere with the establishment of a unified theory that encompasses both sorts of phenomena.

Because the architects of the Modern Synthesis adopted the heuristic conceits that development is completely under genetic control and that characteristics that are shaped even partially by experiences cannot be inherited, they were able to effectively 'blackbox' development; under such an arrangement, an evolutionary theory that is strictly a theory of populations is unproblematic. But, as the last decade has unfolded and the multi-directional flow of information between the molecular, organismic, and population levels of analysis has become apparent (R. Lickliter, personal communication, January $24,2007)$, this limitation of our current evolutionary theory has become increasingly unworkable.

\section{$\underline{\text { Influences across levels of analysis }}$}

In the nearly 100 years since T. H. Morgan concluded that Mendel's and Johannsen's "genes" were on nuclear chromosomes, the influence of molecular factors on the structure and function of organisms has been recognized. In contrast, it is much more recently that scientists have come to understand that organismic factors also have vitally 
important influences on the genome. Although there is little evidence that events experienced during normal development can actually change the sequence of nucleotides in an individual's genome (but see Steele, Lindley, and Blanden, 1998, for controversial evidence of such a phenomenon), it is now clear that non-genetic factors influence the functioning of the genome in a number of ways. For example, non-genetic factors that affect normal phenotypic development include methylation patterns, hormone exposure, and sensory stimulation, among others (Harper, 2005; Jablonka \& Lamb, 2005). As indicated above, several of the mechanisms by which these factors regulate gene expressioneffectively turning genes 'on' or 'off' — are now well understood; such mechanisms provide ways for our experiences to alter our characteristics by altering the functioning of our genes. Similarly, the discovery of 'immediate early genes' has alerted us to the possibility that gene expression can be influenced directly by factors in the environment. Environmental stimuli already known to influence genetic functioning include stress (Glaser et al., 1990), light experienced during the normally-dark phase of circadian cycles (Rusak, Robertson, Wisden, $\&$ Hunt, 1990), and the tactile stimulation that rat pups experience when their mothers groom them in their first week of postnatal life (Meaney \& Szyf, 2005).

Importantly, some of these phenomena produce effects that can be transmitted across generations, thus providing an avenue by which non-genetic factors experienced during an individual's lifetime can have effects on descendant generations. The effects of specific experiences on genetic functioning will, in certain cases, not appear in descendants unless the descendants have experiences similar to the ones that produced the effects in the ancestral generation. ${ }^{5}$ But in other cases, an experience at some point in an individual organism's life can have effects that alter the development of descendant generations, even 
if the descendant generations develop in an environment free of the factor that originally affected their ancestor.

For example, Champagne \& Meaney (2006) have reported that female rats that ordinarily exhibit high levels of maternal licking and grooming will, after having been stressed during pregnancy, dramatically reduce their licking and grooming of their newborn pups, and ultimately wind up with abnormally fearful adult male offspring and with adult female offspring that themselves are abnormally low on measures of licking and grooming. Interestingly, the adult grand-pups — the offspring of these abnormal offspring — will likewise be fearful if they are male, and low licking/grooming mothers if they are female. But perhaps most striking is the finding that when the original stressed females are mated a second time so as to give birth to pups that did not experience stress as fetuses, the offspring will nonetheless show the effects of the mothers' earlier stressful experiences - presumably because the mothers continue to exhibit low levels of licking and grooming - and the effect will likewise continue to be apparent in the behaviors of the grand-pups. Clearly, the experience of stress during pregnancy can change female rats' behaviors in a way that can subsequently be passed from generation to generation, even if later generations never experience gestational stress themselves. Additional work in the laboratory of Michael Meaney (e.g., Meaney \& Szyf, 2005; Weaver et al., 2007) has demonstrated how maternal behaviors can permanently influence gene expression in descendant generations by environmentally 'programming' the genome in ways that lead to effects that persist across generations. Analogous findings from studies of the transgenerational effects of exposure to environmental toxins have likewise led to the conclusion that environmental factors can “reprogram the germ line” (Anway, Cupp, Uzumcu, \& Skinner, 2005; Crews et al., 2007) 
Taken together, it is now clear that factors operating at the level of the genes and factors operating at the level of the organism mutually influence one another, and that factors operating at both levels influence the development and maintenance of behavioral phenotypes.

The same symmetrical relations characterize influences at the level of the organism and at the level of the population of which the organism is a part. Clearly, the behaviors of particular animals can have population-level effects, effects that can influence evolution. If a mutation in a small group of individuals within a population gives them a reproductive advantage over their conspecifics, then all other things being equal, the descendant populations will, on average, be more like the mutated ancestors than the non-mutated ancestors. But even without any mutations, if a small group of individuals within a population begins to behave in a novel, adaptive way_perhaps as a reaction to other animals migrating into their traditional environments, or as a reaction to large scale meteorological events like global warming_-similar consequences could ensue.

For instance, Michel and Moore (1995) have described how some troops of landdwelling Japanese monkeys living near the ocean began to receive food from human tourists, after which they started washing the food in the sea, a novel behavior for this species. Ultimately, this behavior led to an increase in the quantity and types of seafood they consumed, and led to more swimming and diving than had previously been observed. If such behaviors prove beneficial to these innovators, it is easy to imagine other members of the population ultimately behaving similarly_monkeys being known for their tendency to imitate, after all-leading to the novel behavior characterizing the entire population. Importantly, Michel and Moore go on to point out the potential evolutionary consequences 
of such novel behaviors: these monkeys could begin to subsist on seafood alone if the tourists stop feeding them one day, and once they begin to exploit this novel niche, the possibility of "extending their range by swimming to nearby islands" (p. 161) suddenly emerges, an event that would entail clear evolutionary implications, given how reproductive isolation influences evolution.

Likewise, behaviors and habitats that characterize populations of animals have very important influences on the development of individual organisms. As Lickliter and Berry (1990) have pointed out, the species-typical environments in which mature animals raise their offspring - that is, the habitats characteristically occupied by those populations — are structured in ways that positively contribute to phenotypic outcomes; perceptual arrays experienced by all normal juveniles of a species can have important effects on the development of those individuals' perceptual competencies. Similarly, modes of communication can be thought of as phenotypic features of populations, features that are present in species-typical environments and that profoundly influence the characteristics of individuals developing in those contexts. Of course, the traits of the individuals subjected to these developmental influences have evolutionary consequences in turn, since these are traits that natural selection can then operate on; it is, after all, natural selection operating on individuals that gives rise to changes in frequencies of genes in populations.

Thus, events occurring at the level of the genome affect the development of the individual organism, and events experienced by the organism affect the functioning of the genome; likewise, events occurring at the level of the organism affect the characteristics of the population, and characteristics of populations affect the development of individual organisms. These dual bidirectional flows of information seem consonant with the intuition 
of virtually all biologists who wrote in the 50 years following the publication of Darwin's Origin of Species; there is a close and important relationship between individual development and evolution. But since the formulation of the Modern Synthesis 70 years ago, developmental phenomena have been seen as being under strict genetic controlsubject to information flowing unidirectionally, from the genome to the organism - and evolution has been restrictively defined as a population-level phenomenon only.

The history of ideas about development and evolution has left us with widespread conceptual confusion

As a result of the structure and assumptions of the Modern Synthesis, it is possible to read about studies using the techniques of population genetics in almost any current journal of psychology or biology; but even though such techniques measure variability across populations, they provide no understanding at all of the mechanical causes of the individual development that must be responsible for that variability. To choose just one representative example from a journal of psychological science, Deater-Deckard et al. (2006) recently issued a report of a longitudinal behavioral genetic analysis of task persistence in nearly 200 pairs of twins tested first in Kindergarten or $1^{\text {st }}$ grade, and then re-tested 1 year later. The authors wrote in their introduction "knowing whether and how the genetic ... and ... environmental influences on task persistence contribute to stability and change yields more precise predictions about how specific genes and environments operate in development" (p. 499). However, twin studies are not able to illuminate anything about how genes and environments operate in development, because such studies are designed to account for variability across populations, not to explore the genetic and non-genetic factors that mechanically cause development in individuals (Moore, 2006). 
Reporting on their results, Deater-Deckard et al. (2006) wrote that they had detected stability in individual differences in task persistence that were "accounted for predominantly by stable genetic influences" (p. 502), and they concluded that "genetic variation appears to be very important" when trying to explain this stability. To their credit, these researchers were careful to point out that their data do "not allow us to infer a causal direction of influence, given that these data are correlational" (p. 503). Nonetheless, although their final paragraph again acknowledges that "causality cannot be inferred from quasi-experimental behavioral genetic designs," the words immediately preceding this caveat assert "that the causes of...stability shift with development — from shared environmental influences in early childhood to genetic influences in middle childhood" (p. 503), as if the study they conducted actually does tell us something about the causes of developmental stability. Because all quantitative behavioral genetic designs are quasi-experimental—meaning that causality cannot be inferred from any such design - the confusion introduced and propagated by such studies, many of which make inappropriate causal claims like Deater-Deckard et al.'s, remains no small problem.

Finding our way out of this predicament will not be easy. The first step might very well entail acknowledgement by both biologists and psychologists that the data of molecular and developmental biology do not permit the existence of genes 'for' full-blown phenotypic traits (Jablonka \& Lamb, 2005; Lickliter \& Honeycutt, 2003; Moore, 2001; Robert, 2006). This should be easier for psychologists, because it is obvious that non-genetic factors contribute to the development of characteristics that are even minimally complex, and all psychological characteristics rise to this level of complexity. Because the phenotypes that biologists study can sometimes be as simple as the presence or absence of a protein in an 
organism's body, it would seem that it might be more difficult for them to abandon the idea of genes 'for' characteristics; but because the shape of a protein molecule —often considered to be the direct product of genetic activity - is influenced by non-genetic factors such as the temperature and $\mathrm{pH}$ in the intracellular environment in which the protein is built (Johnston, 1987), even simple proteins cannot be thought of as existing in an organism prior to the realization of the developmental processes needed to construct them. Fortunately, more and more biologists seem to understand this point.

Once we recognize the importance of developmental events in the construction of the phenotypes that natural selection can operate on, we will be in a position to begin elaborating a theory of evolution able to explain biological and psychological phenomena in a unified way. This will be the first step in a long reconceptualization process, though, because one of the bedrock notions in our current theory of evolution is Weismann's doctrine that developmental events cannot play a role in evolution. As soon as this error is acknowledged, however, the definition of evolution as a process entailing only changes in the frequency of genes in populations will need to be changed.

The definition of evolution that emerges from this shake up will likely shift scientists' focus from genotypes to phenotypes, and will require an expanded view of how phenotypes are transmitted from generation to generation. Rather than maintaining that genetic material alone is inherited by descendant generations, the emerging theory will have room for the idea that species-typical environments are effectively inherited by descendant generations as well (albeit through a very different mechanism); Griffiths and Gray have explicated this idea in several publications $(1994,2001)$. And once this idea is in place, the belief that natural selection operates on genes alone will give way to the 
belief that natural selection operates on gene-environment complexes, structures that give rise — in development— to adaptive phenotypes. Gottlieb first referred to such complexes as developmental manifolds in 1971.

These new ideas will not come to characterize entire fields of study quickly; psychologists — and biologists, to a somewhat lesser extent (as ironic as that might seem) - remain enthralled by the idea that evolutionary processes have provided us with genomes that dictate the development of characteristics that were adaptive for our evolutionary ancestors living in Africa in the Pleistocene epoch (e.g., Faulkner, Schaller, Park, \& Duncan, 2004). But change will come as the data of molecular and developmental biology continue to undermine the foundations of our current theory of evolution by calling into question the assumption that genetic factors can determine the appearances of our characteristics (Kuhn, 1996). There is obviously much work to be done in the interim, but these new ideas hold out the possibility of forging a theory of evolution that is consistent with the known facts of development. Such a theory would encourage an understanding of population-level phenomena that can actually inform, and be informed by, our understandings of organism-level phenomena. 


\section{References}

Anway, M. D., Cupp, A. S., Uzumcu, M., \& Skinner, M. K. (2005). Actions of endocrine disruptors and male fertility. Science, 308, $1466-1469$.

Appleman, P. (2001). Darwin: A Norton critical edition (3rd ed.). New York: Norton

Ariew, A. (in press). Population thinking. In D. Hull and M. Ruse (Eds.), Oxford companion to philosophy of biology. Cambridge University Press.

Barker, G. (1993). Models of biological change: Implications of three studies of "Lamarckian" change. In P. P. G. Bateson, P. H. Klopfer, \& N. S. Thompson (Eds.), Perspectives in ethology (Vol. 10): Behavior and evolution. New York: Plenum Press.

Baron-Cohen, S. (1995). Mindblindness: An essay on autism and theory of mind. Cambridge, MA: MIT Press.

Bernard, L. C., Mills, M., Swenson, L., \& Walsh, R. P. (2005). An evolutionary theory of human motivation. Genetic, Social, and General Psychology Monographs, 131, 129 - 184.

Bouchard, T. J., \& Segal, N. L. (1985). Environment and IQ. In B. B. Wolman (Ed.), Handbook of intelligence: Theories, measurements, and applications. New York: Wiley.

Brena, R. M., Huang, T. H-M., \& Plass, C. (2006). Toward a human epigenome. Nature Genetics, 38, $1359-1360$.

Buckley, D., Alcobendas, M., García-París, M., \& Wake, M. H. (2007). Heterochrony, cannibalism, and the evolution of viviparity in Salamandra salamandra. Evolution \& Development, 9, 105 - 115.

Champagne, F. A., \& Meaney, M. J. (2006). Stress during gestation alters postpartum maternal care and the development of the offspring in a rodent model. Biological Psychiatry, 59, $1227-1235$. 
Chomsky, N. (1975). Reflections on language. New York: Pantheon Books.

Cosmides, L. (1989). The logic of social exchange: Has natural selection shaped how humans reason? Studies with the Wason selection task. Cognition, 31, 187-276.

Crews, D., Gore, A. C., Hsu, T. S., Dangleben, N. L., Spinetta, M., Schallert, T., et al. (2007). Transgenerational epigenetic imprints on mate preference. Proceedings of the National Academy of Sciences of the United States of America, 104, 5942 - 5946.

Crick, F. H. C. (1958). On protein synthesis. Symposia of the Society for Experimental Biology, XII (The biological replication of macromolecules), 138 - 163. Cambridge, England: Cambridge University Press.

Crick, F. (1970). Central dogma of molecular biology. Nature, 227, $561-563$.

Cuatrecasas, P., Lockwood, D. H., \& Caldwell, J. R. (1965). Lactase deficiency in the adult. Lancet 1 (7375), $14-18$.

Darwin, C. (1859/1991). On the origin of species by means of natural selection. Amherst, NY: Prometheus books.

Deater-Deckard, K., Petrill, S. A., Thompson, L. A., \& DeThorne, L. S. (2006). A longitudinal behavioral genetic analysis of task persistence. Developmental Science, 9, 498 - 504.

de Beer, G. R. (1958). Embryos and ancestors $\left(3^{\text {rd }}\right.$ ed.). London: Oxford University Press.

De Cruz, H. (2006). Why are some numerical concepts more successful than others? An evolutionary perspective on the history of number concepts. Evolution and Human Behavior, 27, $306-323$.

Dennett, D. C. (1995). Darwin's dangerous idea: Evolution and the meanings of life. New York: Simon and Schuster. 
Durham, W. H. (1991). Coevolution: Genes, culture, and human diversity. Stanford, CA: Stanford University Press.

Eisenberg, L. (2004). Social psychiatry and the human genome: Contextualising heritability. British Journal of Psychiatry, 184, $101-103$.

Faulkner, J., Schaller, M., Park, J. H., \& Duncan, L. A. (2004). Evolved disease-avoidance mechanisms and contemporary xenophobic attitudes. Group Processes \& Intergroup Relations, 7, $333-353$.

Garstang, W. (1922). The theory of recapitulation: A critical re-statement of the biogenetic law. Journal of the Linnean Society of London, Zoology, 35, 81-101.

Gilbert, S. F. (2003). The reactive genome. In G. B. Müller \& S. A. Newman (Eds.), Origination of organismal form: Beyond the gene in developmental and evolutionary biology (pp. 87 - 101). Cambridge, MA: MIT Press.

Glaser, R., Kennedy, S., Lafuse, W. P., Bonneau, R. H., Speicher, C., Hillhouse, J., et al. (1990). Psychological stress-induced modulation of interleukin 2 receptor gene expression and interleukin 2 production in peripheral blood leukocytes, Archives of General Psychiatry, $47,707-712$.

Gottlieb, G. (1971). Development of species identification in birds: An inquiry into the prenatal determinants of perception. Chicago: University of Chicago Press.

Gottlieb, G. (1987). The developmental basis of evolutionary change. Journal of Comparative Psychology, 101, $262-271$.

Gottlieb, G. (1992). Individual development and evolution: The genesis of novel behavior. New York: Oxford University Press. 
Gottlieb, G. (2004). Normally occurring environmental and behavioral influences on gene activity: From central dogma to probabilistic epigenesis. In C. G. Coll, E. L. Bearer, \& R. M. Lerner (Eds.), Nature and nurture: The complex interplay of genetic and environmental influences on human behavior and development (pp. 85 -106). Mahwah, NJ: Lawrence Erlbaum Associates Publishers.

Gould, S. J. (1977). Ontogeny and phylogeny. Cambridge, MA: The Belknap Press of Harvard University Press.

Gould, S. J. (2002). The structure of evolutionary theory. Cambridge, MA: The Belknap Press of Harvard University Press.

Griffiths, P. E., \& Gray, R. D. (1994). Developmental systems and evolutionary explanation. The Journal of Philosophy, XCI, 277-304.

Griffiths, P. E., \& Gray, R. D. (2001). Darwinism and developmental systems. In S. Oyama, P. E. Griffiths, \& R. D. Gray (Eds.), Cycles of contingency: Developmental systems and evolution (pp. 195 - 218). Cambridge, MA: MIT Press.

Guttmacher, A. E. \& Collins, F. S. (2005). Realizing the promise of genomics in biomedical research. The Journal of the American Medical Association, 294, 1399 - 1402.

Haeckel, E. (1866). Generelle morphologie der organismen: Allgemeine grundzüge der organische formen-wissenschaft, mechanisch begründet durch die von Charles Darwin reformirte descendenz-theorie, 2 vols. (Georg Reimer, Berlin).

Hampson, E., van Anders, S. M., \& Mullin, L. I. (2006). A female advantage in the recognition of emotional facial expressions: Test of an evolutionary hypothesis. Evolution and Human Behavior, 27, $401-406$. 
Harper, L. V. (2005). Epigenetic inheritance and the intergenerational transfer of experience. Psychological Bulletin, 131, 340 - 360.

Hogben, L. T. (1945). Nature and nurture, being the William Withering Memorial Lectures. London: G. Allen and Unwin Ltd.

Jablonka, E., \& Lamb, M. J. (2005). Evolution in four dimensions: Genetic, epigenetic, behavioral, and symbolic variation in the history of life. Cambridge, MA: MIT.

Johnston, T. D. (1987). The persistence of dichotomies in the study of behavioral development. Developmental Review, 7, 149 - 182.

Johnston, T. D., \& Gottlieb, G. (1990). Neophenogenesis: A developmental theory of phenotypic evolution. Journal of Theoretical Biology, 147, 471 - 495.

Keller, E. F. (2000). The century of the gene. Cambridge, MA: Harvard University Press.

Kuhn, T. S. (1996). The structure of scientific revolutions $\left(3^{\text {rd }}\right.$ ed.). Chicago, IL: University of Chicago Press.

Laland, K. N., Kumm, J., \& Feldman, M. W. (1995). Gene-culture coevolutionary theory: A test case. Current Anthropology, 36, $131-156$.

Laland, K. N., Kumm, J., Van Horn, J. D., \& Feldman, M. W. (1995). A gene-culture model of human handedness. Behavior Genetics, 25, 433 - 445.

Lickliter, R., \& Berry, T. D. (1990). The phylogeny fallacy: Developmental psychology’s misapplication of evolutionary theory. Developmental Review, 10, $348-364$.

Lickliter, R., \& Honeycutt, H. (2003). Developmental dynamics: Toward a biologically plausible evolutionary psychology. Psychological Bulletin, 129, 819 - 835. 
Mayr, E. (1959). Typological versus Population Thinking. In Evolution and Anthropology: A Centennial Appraisal (pp. 409 - 412). Washington: Anthropological Society of Washington.

McComb, K., \& Semple, S. (2005). Coevolution of vocal communication and sociality in primates. Biology Letters, 1, $381-385$.

McNamara, K. J., \& McKinney, M. L. (2005). Heterochrony, disparity, and macroevolution. Paleobiology, 31, $17-26$.

Meaney, M. J. (2007, March). Adaptive phenotypic plasticity in rats: Maternal effects on programming of behavioral and endocrine responses to stress. In B. J. Ellis (Chair), The stress response systems: Integrated evolutionary-developmental perspectives. Symposium conducted at the meeting of the Society for Research in Child Development, Boston, MA.

Meaney, M. J., \& Szyf, M. (2005). Maternal care as a model for experience-dependent chromatin plasticity? Trends in Neurosciences, 28, $456-463$.

Michel, G. F., \& Moore, C. L. (1995). Developmental psychobiology: An interdisciplinary science. Cambridge, MA: MIT.

Mitchell, S. D. (2003). Biological complexity and integrative pluralism. Cambridge: Cambridge University Press.

Montagu, M. F. A. (1962). Culture and the evolution of man. New York: Oxford University Press.

Moore, D. S. (2001). The dependent gene: The fallacy of nature vs. nurture. New York: W.H. Freeman. 
Moore, D. S. (2006). A very little bit of knowledge: Re-evaluating the meaning of the heritability of IQ. Human Development, 49, 347 - 353.

Neumann-Held, E. M. (1998). The gene is dead - Long live the gene: Conceptualizing genes the constructionist way. In P. Koslowski (Ed.), Sociobiology and bioeconomics: The theory of evolution in biological and economic theory (pp. 105-137). Berlin: Springer-Verlag.

Oyama, S. (1992). Transmission and construction: Levels and the problem of heredity. In E. Tobach \& G. Greenberg (Eds.), Levels of social behavior: Evolutionary and genetic aspects: Award winning papers from the Third T. C. Schneirla Conference: Evolution of social behavior and integrative levels. Wichita, Kan: T.C. Schneirla Research Fund.

Pinker, S. (2002). The blank slate: The modern denial of human nature. New York: Viking.

Plomin, R. (1994). Genetics and experience: The interplay between nature and nurture. Individual Differences and Development Series, Volume 6. Thousand Oaks, CA: Sage.

Robert, J. S. (2006). Embryology, epigenesis, and evolution (Cambridge studies in philosophy and biology). New York: Cambridge University Press.

Rusak, B., Robertson, H. A., Wisden, W., \& Hunt, S. P. (1990). Light pulses that shift rhythms induce gene expression in the suprachiasmatic nucleus. Science, 248, $1237-1240$.

Sober, E. (1994). Evolution, population thinking, and essentialism. In E. Sober (Ed.), From a biological point of view: Essays in evolutionary philosophy. New York: Cambridge University Press.

Steele, E. J., Lindley, R. A., \& Blanden, R. V. (1998). Lamarck's signature. Reading, MA: Perseus Books.

Tabery, J. G. (2007). Causation in the nature-nurture debate: The case of genotype-environment interaction. Unpublished doctoral dissertation, University of Pittsburgh, Pittsburgh. 
Tishkoff, S. A., Reed, F. A., Ranciaro, A., Voight, B. F., Babbitt, C. C., Silverman, J. S. et al. (2007). Convergent adaptation of human lactase persistence in Africa and Europe. Nature Genetics, 39, $31-40$.

Waddington, C. H. (1957). The strategy of the genes: A discussion of some aspects of theoretical biology. New York: The Macmillan Company.

Wainwright, M.A., Wright, M.J., Geffen, G.M., Luciano M., \& Martin, N.G. (2005). The genetic basis of academic achievement on the Queensland Core Skills Test and its shared genetic variance with IQ. Behavior Genetics, 35, 133 - 145.

Weaver, I. C. G., D’Alessio, A. C., Brown, S. E., Hellstrom, I. C., Dymov, S., Sharma, S., et al. (2007). The transcription factor nerve growth factor-inducible protein A mediates epigenetic programming: Altering epigenetic marks by immediate-early genes. The Journal of Neuroscience, 27, $1756-1768$.

Yamagata, S., Suzuki, A., Ando, J., Ono, Y., Kijima, N., Yoshimura, K., et al. (2006). Is the genetic structure of human personality universal? A cross-cultural twin study from North America, Europe, and Asia. Journal of Personality and Social Psychology, 90, 987 - 998.

Yamamoto, K. R. (1985). Steroid receptor regulated transcription of specific genes and gene networks. Annual Review of Genetics, 19, 209-252. 
Individuals and Populations 35

Author Note

David S. Moore, Pitzer College.

This paper was written while David Moore was supported by funds provided by the Research and Awards Committee of Pitzer College.

I gratefully acknowledge the assistance of Robert Lickliter, James Tabery, Jason Robert, and Dawn Jones, whose criticisms of an earlier draft of this paper contributed helpfully to its final form.

Correspondence concerning this article can be sent via e-mail to dmoore@pitzer.edu or via traditional mail to David Moore, at Pitzer College, Claremont, CA 91711, USA. 
Individuals and Populations 36 


\section{Footnotes}

${ }^{1}$ Gilbert Gottlieb, to whom this paper is dedicated, was instrumental in helping many in the current generation of developmental psychologists to think about the connections between their work and the work of evolutionary biologists.

${ }^{2}$ There have always been biologists who understood how important context is for gene activity. For example, Wilhem Johannsen, the man who actually coined the word "gene" in 1909, clearly understood that traits are not caused by genes operating independently of developmental "conditions." Likewise, it is apparent from their writings that Lancelot Hogben (1945) and Conrad Waddington (1957) were both keenly aware that developmental outcomes (phenotypes) are always influenced by contextual factors.

${ }^{3}$ Note that such a strategy would permit the integration of approaches that Tabery (2007) has called for, because it could generate information that would explain both the appearance of characteristics in individuals and differences in those characteristics across members of a population. Nonetheless, this strategy will not eliminate the central problem I am outlining in this paper, for at least two reasons. First, adopting this strategy would still leave the extant literature of quantitative behavior genetics explanatorily isolated from literatures on the mechanical causes of development; just because it is possible to identify developmental factors that contribute to differences in phenotypes does not mean that quantitative behavior geneticists - who for the past century have used correlational approaches to account for variation across populations - have done any such thing. As has always been the case, correlations tell us remarkably little about causation. Second, as long as 1) evolution is defined as a change in the frequency of certain genes in a population (i.e., that evolution is strictly a population-level phenomenon) and 2) the 
scientific community persists in accepting as axiomatic the idea that developmental events can influence some of our characteristics but that such so-called "acquired" characteristics cannot influence evolution, an untenable conceptual barrier between developmental and evolutionary phenomena will exist, and will continue to interfere with the construction of a unified theory of biology.

${ }^{4}$ Genotypic differences between individuals that do not give rise to phenotypic differences cannot possibly be subjected to differential selective pressures, and so cannot drive evolution in an active way. Different phenotypes, in contrast, can be subjected to differential selective pressures, but the phenotypes in question always result from developmental processes in which genetic and non-genetic factors collaborate to construct the potentially selectable characteristics.

${ }^{5}$ While such an effect would generally be considered unable to contribute to evolution, some theorists have argued that because all characteristics develop via coaction of both genetic and non-genetic factors, there is no principled way to distinguish between traits that are "inheritable" (and therefore relevant to evolutionary explanation) and traits that are "acquired" during development (and are therefore not relevant to evolutionary explanation). Arguments consistent with this point of view can be found in Griffiths \& Gray (2001) and Moore (2001).

${ }^{6}$ Although the sorts of effects described by Anway et al. (2005) and Crews et al. (2007) would be considered heretical by many biologists steeped in traditional accounts of evolution, Jablonka \& Lamb's (2005) survey of non-genetic systems of information inheritance suggests that biologists can expect to find such effects in their data once they begin to look for them in earnest. 